\title{
Modelling of Time Efficiency in Heterogeneous and Adhoc Networks
}

\author{
Yatendra Singh Bhandari, Yashwant Singh Chauhan, PritiDimri \\ Department of Computer Sc. \& Engineering, GovindBallabh Pant Institute of Engineering \& Technology \\ Ghurdauri, Pauri-Garhwal-246194, Uttarakhand, India \\ Telp-01368-228030, fax-01368-228062
}

\begin{tabular}{l}
\hline Article Info \\
\hline Article history: \\
Received Jan 25, 2018 \\
Revised May 12, 2018 \\
Accepted Jun 16, 2018 \\
\hline Keywords: \\
TE \\
EE \\
ATE \\
PL \\
ALF \\
\hline
\end{tabular}

\begin{abstract}
Heterogeneous Networks are bunch of homogeneous networks base stations grouped together. The term introduced in this research paper Time Efficiency (Te) gives out the information on the heterogeneous networks where most of the data flows in and out. In this paper, a model for evaluating Time Efficiency in heterogeneous network is developed. The common goals of different base stations in a heterogeneous network are towards coverage of area and capability improvement. Base stations in a homogeneous network differs in transmitted power, achievable rate of data, area covered, density of a base station, energy efficiency and time efficiency. To find out the area of most data flow in certain period, Time efficiency can be used as a major factor.
\end{abstract}

Copyright $\odot 2018$ Institute of Advanced Engineering and Science. All rights reserved.

Corresponding Author:

Yatendra Singh Bhandari

Department of Computer Sc. \& Engineering,

GovindBallabh Pant Institute of Engineering \& Technology

Ghurdauri, Pauri-Garhwal-246194, Uttarakhand (India)

telp-01368-228030, fax-01368-228062

Email: 2yatendra@gmail.com

\section{INTRODUCTION}

\subsection{Background}

The 11th annual Cisco Visual Networking Index Global Mobile Data Traffic Forecast (which gives the forecast for 2016 to 2021) [1] projects that there will be a lot more people on Earth using mobile phones in 221 than there are with access to running water. By 2021, more members of the global population will be using mobile phones (5.5 billion) than bank accounts ( 5.4 billion), running water (5.3 billion), or landlines (2.9 billion). It indicates the need of new Infrastructure. It is to be noted that $r$ Low Power Nodes (LPN) plays an important role in such kind of infrastructure [2] because of their higher per area capacity. And also, it is necessary to know, which area is using most data flow and which one is using least to tell about both capacity and energy challenges.

\subsection{Problem}

Future Heterogeneous network areas requires to implement Network Time Efficiency (Te) because it is a primary key in performance indication. Although energy efficiency considers energy consumed by network and also its capabilities related to data load capacity of heterogeneous network (Tao 2010). But we need to know the energy efficiency (EE) in some particular time period for heterogeneous networks and this information will be provided by Time efficiency (Te) model. Research works on wireless cellular networks focuses on practical application of algorithms of network model design (Panayiotis 2012; Amaldi 2008)[3-4]. 


\subsection{Solution}

There has been a lot of surveys on green mobile networks and methods to improve the systems energy efficiency in heterogeneous network (Ayad (2012a) and Xiaofei (2012)) [5-6]. This research paper will further extend the work to find the Te for a particular network in same given time period. This paper shows how it seems for some particular base station to be good for communication, but analyzing its Te we see that it may improved by simple measures. Architecture of heterogeneous network (cellular) is shown below to illustrate the meaning of macro, micro and pico stations in a communication network.

\section{Related Netwrok Models}

\subsection{Propagation Network Model}

Propagation model tells about $\mathrm{Te}$ signal propagation and the power received in system of heterogeneous network. Quality of signals received depends upon loss in path during propagation (PL), loss inpenetration during propagation ( $\beta$ ), pattern of antenna (Ah) in the propagation network and shadowing effect $(\Psi)$. Let the received power of signal be denoted by Prx, for the nth user to a base station from a distance of $r$ units and at an angle $\theta$. It can be described in terms of transmitted power of the base station as (Tesfay et al. (2011))[7]:

$$
\operatorname{Pr} x=P t x n-A L F n
$$

Where, Ptx is the transmitted power and ALF represents the aggregate signal attenuation factor caused by Path Loss (PL), and some outdoor-indoor penetration loss ( $\beta$ ) and also because of radiation pattern $(\mathrm{Ah})$ as well as shadowing effect, ALF for the nth user can be written as:

$$
A L F n(r, \theta)=P L d b(r)+\beta \mathrm{db}+\mathrm{Ahn}(\theta)+\Psi \mathrm{db}
$$

These factors can be obtained by choosing the appropriate path loss model (e.g., (3GPP, 2009))[8].

\subsection{Coverage Network Model}

Cellular models use the concept of propagation model and design the formula according to the aread of cellular coverage. Suppose we have an area with radius R. Now we need to know the minimum power above which communication will occur. Then coverage area for this cell of radius $\mathrm{R}$ will be the area where power received is always above the minimum power required by the network (Pmin). It is stated as (Goldsmith, 2005) [9]:

$$
C=Q(a)+\exp \left(\frac{2-2 a b}{b^{2}}\right) Q\left(\frac{2-a b}{b}\right)
$$

Q-function denotes the probability that a Gaussian random variable $\mathrm{X}$ with mean 0 and variance 1 is greater than $\mathrm{z}$

$$
\mathrm{Q}(\mathrm{z})=\operatorname{prob}(\mathrm{X} \geq \mathrm{z})=\frac{1}{\sqrt{2 \pi}} \int \exp \left(\frac{-x^{2}}{2}\right) d x
$$

And

$$
\mathrm{a}=\frac{\mathrm{P}_{\min }-\mathrm{p}_{x x}(\mathrm{R})}{\sigma_{\mathrm{Ydb}}}, \mathrm{b}=\frac{10 \alpha \log _{10}(\mathrm{e})}{\sigma_{\mathrm{Ydb}}}
$$

Pmindenotes the minimum power where specified throughput is fulfilled. The throughput is equal or higher than $95 \%$ of the maximum throughput for a specified reference measurement channel and can be expressed as Stefania et al. (2011) [10]:

$$
P_{\text {min }}=\mathrm{kTB}+\mathrm{NF}+\mathrm{SINR}_{r e q}+\mathrm{IM}-\mathrm{G}_{d}
$$


Where, kTB denotes the level of thermal noise for a specified noise bandwidth BW. Term NF is used particularly for the maximum noise figure received. SINRreq is said to be the interference signal and noise ratio requirement. IM stands for the implementation margin and the Gdgives out gain in diversity (Stefania 2011).

\subsection{Power Network Model}

Practical knowledgeof data transfer in wireless heterogeneous networks or cellular networks shows that for network establishment and the network which is currently in use, the power consumption does not depend on the data load held by the heterogeneous network(Auer 2011; Micallef 2012; Skillermark 2011) [11-13]. We are assuming static consumption of power and ideal conditions for traffic of data, the Pci (average power consumption) for a BS is denoted as (Richter (2009) [14]):

$$
\mathrm{Pc}_{i}=\mathrm{N}_{\mathrm{sec}} N_{a n t}\left(A_{i} P_{t x}+\mathrm{B}_{j}+\mathrm{P}_{B H i}\right)
$$

Nsec is said to be number of sectors and Nant is said to be the number of antennas per sector for a particular base station. Pci is the average of total power of each base station and Ptx is the transmitted power for each base station. The coefficient Ai represents that part of the Pci which is directly proportional to the transmitted power from a base station, while $\mathrm{Bi}$ represents that part of power that is consumed without any dependency to the average transmitted power from a base station. These are very important factors which describes the information of energy efficiency for a base station (Bambos and Rulnick, 1997). PBHiis added to determine the power consumption which is done during the transmission from backhauling fiber (Tombaz et al., 2011) [15].

\subsection{Energy Efficiency Network Model}

Energy Efficiency (EE) can be stated as total amount of delivered data upon the total consumedpower (Chockalingam and Zorzi, 1998) [16], expression for EE can be given as:

$$
E E=\frac{\text { Overall data rate }}{\text { Total power consumed }}=\frac{R T}{P C T}
$$

RT isdata rate,

$$
R n=\sum_{(k=1)}^{K} r^{k} n
$$

Where, $\mathrm{K}$ amounts to the total sub channels given for $\mathrm{n}$ users. The total data rate for all users can be written as (Miao et al. (2011)) [17]:

$$
R t=\sum_{(n=1)}^{N} R n
$$

Data given to each user can be described as a function of received power:

$$
\mathrm{Rn}=B W n \log 2\left(1+\frac{\operatorname{Prxn}}{\operatorname{In}}\right)
$$

Hence, the total data rate flow for all users for some base station in heterogeneous network can be written as:

$$
\mathrm{Rt}=\eta \sum_{n=1}^{N} \mathrm{Nrb} \log 2\left(1+\frac{\operatorname{Prxn}}{\operatorname{In}}\right)
$$

The $\eta$ normally equals to 1 (correction factor) (Harri and Antti, 2009)[18]. From here the EE of a specific base station with consumed power Pc can then be written as:

$$
\mathrm{EEi}=\frac{R t, i}{P c, i}
$$

The above equation gives us the required energy efficiency of a station. 


\subsection{Time Efficiency Network Model}

The above mentioned EE model gives the idea of efficiency of particular heterogeneous network in an area. We need to find the maximum utilized heterogeneous network area from many areas. For that we need to calculate the efficiency in some given time interval. Let us assume THET to be the time period for overall data transfer of a heterogeneous network, then Time efficiency can be calculated as:

$$
\mathrm{Te}=\frac{\text { EEhet }}{\text { Thet }}
$$

The unit of Te is then bits per Joule per sec. Concept of Te came from the fact that suppose two stations have some EE $(4.8,6.7)$. And if time taken to complete the whole communication is THET $(1,3)$ units. Then although it seems that second station has more EE so it is beneficiary but it is not the truth. Because first one is doing work but in very less time period. For a single time unit First station EE in one unit of time is 4.8 while second station has EE in one unit as 2.23 . This whole example is practically seen in simulation done in result section.

BSs consists of one Macro station and many sub macro station and also many pico stations. Data rate is to be calculated for all station and also power consumed is to be calculated for all stations. Energy efficiency of a heterogeneous network with single macro base station, $\mathrm{M}$ micro base stations and $\mathrm{P}$ pico base stations can be written as:

$$
\text { EEhet }=\frac{\text { Rmacro }+\sum_{(M=1)}^{M} \text { Rmicro }+\sum_{(P=1)}^{P} \text { Rpico }}{\text { Pmacro }+\sum_{(M=1)}^{M} \text { Pmicro }+\sum_{(P=1)}^{P \text { Ppico }}}
$$

EEHET denotes the energy efficiency of the whole heterogeneous network. And if we have the THET, we can calculate the time efficiency for the same as follows:

$$
T e=\frac{\frac{\text { Rmacro }+\sum_{(M=1)}^{M} \text { Pmicro }+\sum_{(P=1)}^{P} \text { Rpico }}{\text { Pmacro }+\sum_{(M=1)}^{M} \text { Pmicro }+\sum_{(P=1)}^{P} \text { Ppico }}}{T(\text { HETEROGENEOUS })}
$$

Area time efficiency can also be calculated according to Area energy efficiency (AEE) which is defined as the bit/Joule/unit area. The AEE for a certain base station can be expressed as:

$$
A E E i=\frac{E E i}{A B s, i},
$$

Where, EEiand ABS, idenote the EE in bit/Joule (Wang and Shen, 2010)[19].

In the similar way we can find the Area Time efficiency (ATE). Its unit is given as bit/joule/second/unit area. The ATE for a heterogeneous network area can be sated as:

$$
A T E i=\frac{T e, i}{A B s, i}
$$

\section{RESULTS AND ANALYSIS}

Now we move to some simulations and results based on Time Efficiency factor.

\subsection{Simulation Setup}

Study of HetNet BSs is simulated according to their respective parameters. BSs are setup in their area according to the radius they need for settlement. BSs may differ in terms of transmit power for macro base station $(46 \mathrm{dBm})$, micro base stations $(35 \mathrm{dBm})$ and pico base stations $(30 \mathrm{dBm})$ [20] respectively. UEs are assumed to be uniformly distributed within the radius of BSs and bandwidth for the investigated LTE downlink scenario is set to $10 \mathrm{MHZ}$ at carrirer frequency of $2.6 \mathrm{GHz}$ [21].Assuming negligible path loss for an ideal case of HetNet BSs, other parameters can be found in Table 1. 
Table 1. Simulation Parameters

\begin{tabular}{ll}
\hline \multicolumn{1}{c}{ PARAMETER } & \multicolumn{1}{c}{ VALUE } \\
\hline Carrier waves frequency & 2.6 \\
Transmission Bandwidth & $10 \mathrm{MHz}$ \\
Transmitted powerfor macro, micro & $1: \mathrm{BS}_{1}=>46 \mathrm{dBm}, 35 \mathrm{dBm}, 30 \mathrm{dBm}$ \\
and pico for three BSs & $2: \mathrm{BS}_{2}=>$ \\
& $3: \mathrm{BS}_{3}=>$ \\
Channel model & $3 \mathrm{G} \mathrm{PP}$ Typical Urban \\
Penetration Loss & $20 \mathrm{~dB}$ \\
Counting of sectors for macro, micro, & $3,1,1$ \\
pico base stations & \\
Propagation Noise figure & $9 \mathrm{~dB}$ \\
Parameters for consumed power & $\mathrm{Macro:} \mathrm{Ai}=21 ; \mathrm{Bi}=354.44$ \\
& $\mathrm{Micro:} \mathrm{Ai}=7.84 ; \mathrm{Bi}=71.5$ \\
& Pico: $\mathrm{Ai}=5.5 ; \mathrm{Bi}=38$ \\
\hline
\end{tabular}

The EE and Te has been calculated for three BSs assuming that all the resources are allocated to that BSs and ideal conditions are assumed for inspection.

\subsection{Simulation Steps}

As depicted in Figure 1, simulation Steps in Time Efficiency factor.

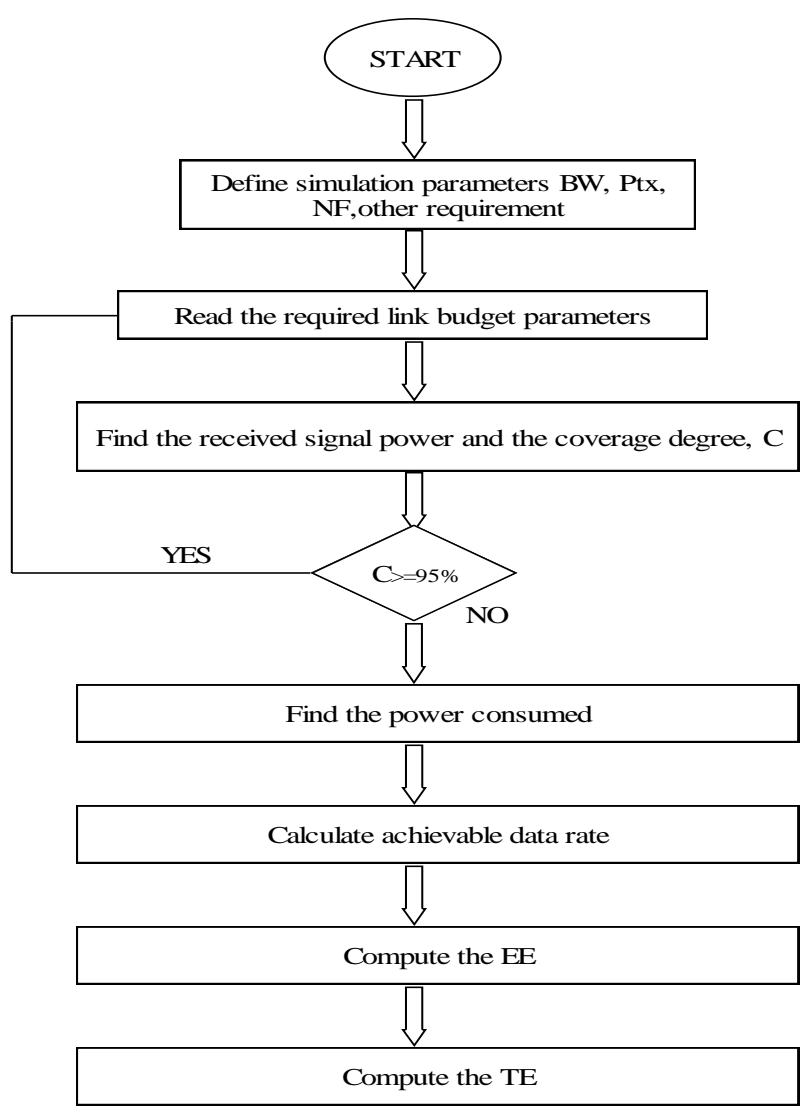

Figure 1. Simulation Steps

\subsection{Simulation Result}

Some results to verify this theoretical concept and its effectiveness are presented in this sections. The performance of the HetNets from the perspective of $\mathrm{EE}$ and then from the perspective of Te is discussed and verification is done under various simulation configurations taking some ideal conditions. 


\subsection{Checking Efficiency in Specified Time Period}

A graph of EE vs Time period gives us the proper measurement of EE in time intervals. According to which we will get to know how much our setup of network will be able to cope up in perspective of time requirements, i.e. speed.

\subsection{Time Efficiency}

Parameters used for three base stations in for simulation are described in table:

Tabe 2. Time duration

\begin{tabular}{lllllll}
\hline S.No. & $\mathrm{P}_{\mathrm{tx}}$ macro & $\mathrm{P}_{\mathrm{tx}}$ micro & $\mathrm{P}_{\mathrm{tx}}$ pico & $\mathrm{EE}$ & Time duration & Te \\
\hline 1 & 46 & 30 & 30 & 6.7 & 5 & $1.34 /$ unit \\
2 & 35 & 20 & 18 & 3.8 & 1 & $3.8 /$ unit \\
3 & 56 & 27 & 20 & 5.9 & 2 & $2.95 /$ unit \\
\hline
\end{tabular}

EE and Te are calculated as the given formulas explained in SYSTEM MODEL section. Time duration is the time period of one whole independent communication being done through network. Although EE of first BSs is greater then other two BSs but the time taken to complete a single task is much more than as compared to second or third model and so overall efficiency of system goes down.

Graphical implementation of this simulation is given in Figure 2.

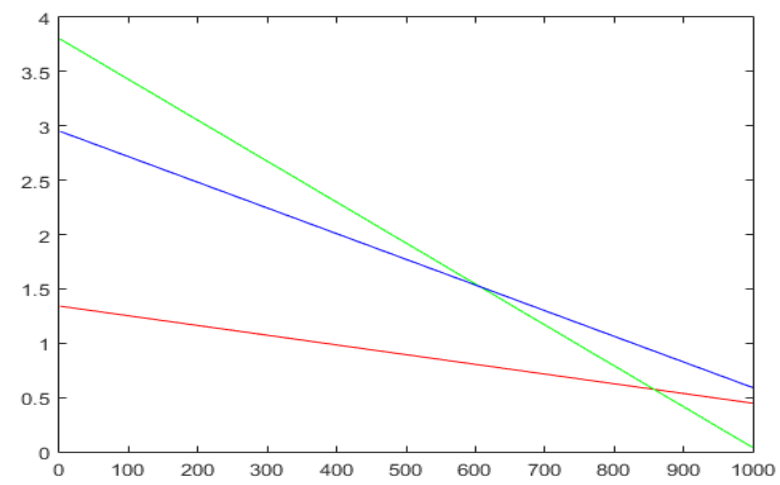

Figure 2. TE for three substation with different macro, micro and pico stations

The $\mathrm{Y}$-axis of the graph shows time energy efficiency in bits/joule/sec and $\mathrm{X}$-axis is time increasing constantly. There are three substation shown in graph, first is red, second is green and third is blue. It is clearly seen from the above table that although EE of first Bs is greater but it takes a very long time and so itsTe is less, but at same time second Bs succeeds due to high Te. So we can use the second model to be implemented to any heterogeneous network.

Table 3. Rate of power can also be seen by plotting the graph between time and power rate

\begin{tabular}{ccccccc}
\hline S.No. & $\mathrm{P}_{\mathrm{tx}}$ macro & $\mathrm{P}_{\mathrm{tx}}$ micro & $\mathrm{P}_{\mathrm{tx}}$ pico & EE & Time duration & Te \\
\hline 1 & 46 & 30 & 30 & 6.7 & 5 & $1.2^{*} 10^{\wedge} 4 /$ unit \\
2 & 35 & 20 & 18 & 3.8 & 1 & $1.0^{*} 10^{\wedge} 4 /$ unit \\
3 & 56 & 27 & 20 & 5.9 & 2 & $1.4^{*} 10^{\wedge} 4 /$ unit \\
\hline
\end{tabular}

The Y-axis of the following graph shows the power rate which is decreasing continuously with the increase in $\mathrm{X}$-axis whixh denotes time (units). From this graph it can be concluded that where power factor is more important, we prefer to use less power and give less importance to time. This case practically can be seen in rural areas. 


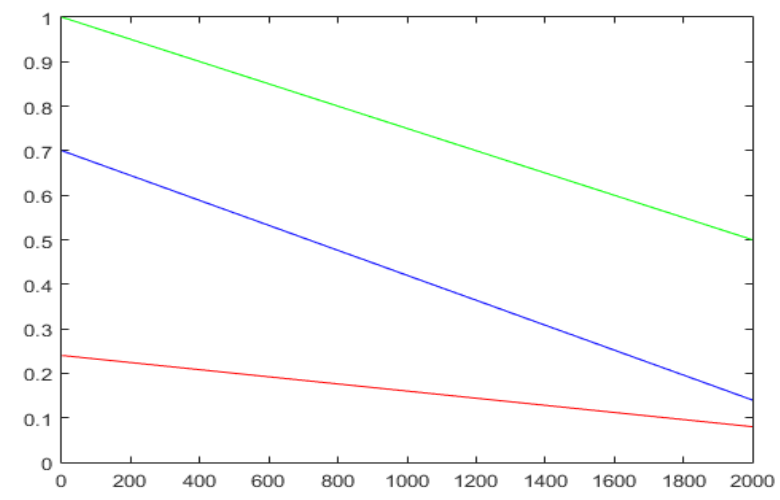

Figure 3. The power rate shows the consumption of power per unit time

So if to some area power problem exists, then they should use the parameters of first model, because when power is not available then time factor may get neglected.

\section{RESULT}

We see that when time is important factor then we can take out Te of models and can judge of which model is to be implemented, but when we have less power then we must take out the plotting's of power rate and see which one is suitable for that area, In above case is time importance is neglected than first model is best to choose. Also for some area we can have third model where power is also in average and time also plays some important role.

\section{CONCLUSION}

In this research paper, we have investigated theTime Efficiency (Te) of a heterogeneous network, which particularly consists of macrocell mixed with many microcells and picocell base stations. Mainly the contribution of paper is in deriving an equation for Te and concluding that if there exists an optimal HetNet model, then it can be send providing a method of how to develop a better heterogeneous network.

\section{REFERENCES}

[1] "Cisco Visual Networking Index: Global Mobile Data Traffic Forecast Update", 2016-2021 White Paper. Document ID:1454457600805266(2017).

[2] "Modeling of Energy Efficiency in Heterogeneous Network". Research Journal of Applied Sciences, Engineering and Technology 6(17): 3193-3201, 2013 ISSN: 2040-7459; e-ISSN: 2040-7467.

[3] "A Practical Approach to Energy Efficient Communications in Mobile Wireless Networks". Mobile Networks and Applications 17(2):267-280 • April 2012.

[4] Amaldi, E., A. Capone and F. Malucelli, 2008. "Radio Planning and Coverage Optimization of 3G Cellular Networks". Wirel. Netw. 14(4): 435-447.

[5] Ayad, A.A., T.S. Kiong, J. Koh, D. Chieng and A. Ting, 2012a. "Energy efficiency of heterogeneous cellular networks: A review". J. App. Sci., 12(14): 1418-1431.

[6] Ayad, A.A., T.S. Kiong, J. Koh, D. Chieng and A. Ting, 2012b. "Energy efficiency and cell coverage area analysis for macrocell networks". IEEE International Conference on Future Communication Networks (ICFCN), pp: $1-6$.

[7] Tesfay, T.T., R. Khalili, J.Y. Le Boudec, F. Richter and A.J. Fehske, 2011. "Energy saving and capacity gains of micro sites in regular LTE networks: Downlink traffic layer analysis". 6-th ACM Workshop on Performance Monitoring and Measurement of Heterogeneous Wireless and Wired Networks, pp: 83-91.

[8] 3GPP, 2009. “T. S. G. R. A. Network. Tr 36.814 further advancements for e-utra: Physical layer spects (release 9). 3rd Generation Partnership Project Tech. Rep.

[9] Goldsmith, A., 2005. "Wireless Communications". Cambridge University Press, New York.

[10] Stefania, S., I. Toufik and M. Baker, 2011. "LTE - The UMTS Long Term Evolution: From Theory to Practice". 2nd Edn., John Wiley and Sons Ltd., UK.

[11] Auer, G., V. Giannini, C. Desset, I. Godor, P. Skillermark, M. Ollsson, M.A. Imran, D. Sabella, M.J. Gonzalez, O. Blume and A. Fehske, 2011. "How much energy is needed to run a wireless network". IEEE T. Wirel. Commun., 18(5): 40-49. 
[12] Micallef, G., L. Saker, S.E. Elayoubi and H.O. Sceck, 2012. "Realistic energy saving potential of sleep mode for existing and future mobile networks". J. Communs., 7(10): 740-748.

[13] Skillermark, P., M. Olsson, Y. Jading, G. Auer, V. Giannini, M.J. Gonzalez and C. Desset, 2011. "System level energy efficiency analysis in cellular networks". Proceedings of Future Network \& Mobile Summit 2011, Warsaw, Poland, IIMC International Information Management Corporation, pp: 1-8.

[14] Richter, F., A.J. Fehske and G.P. Fettweis, 2009. "Energy Efficiency Aspects of Base Station Deployment Strategies for Cellular Networks". Vehicular Technology Conference Fall (VTC 2009-Fall), IEEE 70th, pp: 1-5.

[15] Tombaz, S., P. Monti, K. Wang, V. Anders, M. Forzati and J. Zander, 2011. "Impact of backhauling power consumption on the deployment of heterogeneous mobile networks". Proceedings of the Global Telecommunications Conference, December 5-9, pp: 1-5.

[16] "Modeling of Energy Efficiency in Heterogeneous Network".( September 20, 2013)( AyadAtiyahAbdulkafi, S.K. Tiong, David Chieng, Alvin Ting, Abdulaziz M. Ghaleb and J. Koh).

[17] Miao G., N. Himayat, G. Li and S. Talwar, 2011. "Distributed interference-aware energy-efficient power optimization. IEEE T". Wireless Commun., 10(4): 1323-1333.

[18] Harri, H. and A. Toskala, 2009. "LTE for UMTS: OFDMA and SC-FDMA based Radio Access". John Wiley \& Sons, UK.

[19] Wang, W. and G. Shen, 2010. "Energy efficiency of heterogeneous cellular network". Proceeding of IEEE 72nd Vehic. Technol. Conf. (VTC Fall), pp: 1-5.

[20] "LTE Small Cell Optimization: 3GPP Evolution to Release 13".HarriHolma, Antti Toskala, JussiReunanen.(September 21 2015).

[21] "Use Cases for the 2.5/2.6 GHz Spectrum: Options for TDD Band 38”.Frank Rayal: January 16, 2012. 